\title{
Platelet count and -indices as postpartum haemorrhage risk factors: a retrospective cohort study
}

\author{
Wobke van Dijk ${ }^{1}$, Jelle Nijdam ${ }^{1}$, Saskia Haitjema ${ }^{1}$, Mark de Groot ${ }^{1}$, Albert Huisman ${ }^{1}$, \\ Marieke Punt ${ }^{1}$, Annemiek Evers ${ }^{1}$, Roger Schutgens ${ }^{1}$, A. Titia Lely ${ }^{1}$, and Karin van Galen ${ }^{1}$ \\ ${ }^{1}$ Universitair Medisch Centrum Utrecht
}

November 6, 2020

\begin{abstract}
Objective: To study the relation between platelet parameters and severe postpartum haemorrhage (SPPH). Design: Retrospective cohort study. Setting: Birth centre of the University Medical Centre Utrecht. Population: 23,205 deliveries between 2009 and 2017. Methods: The predictors platelet count, mean platelet volume (MPV), plateletcrit, platelet distribution width (PDW), and immature platelet fraction (IPF) were measured within 72 hours prior to delivery. Multiple imputation was performed for missing data. Odds ratios were adjusted (aOR's) for maternal age, multiple gestation, macrosomia, induction of labour, and preeclampsia. Main outcome measures: Severe postpartum haemorrhage ([?]1,000mL of blood loss within 24 hours after delivery) Results: Of the 2,402 (10.4\%) women with thrombocytopenia (<150*109/L), 10.3\% developed SPPH, compared to $7.6 \%$ of women with a normal platelet count (aOR: 1.34, 95\%-CI: 1.14-1.57). Women with a platelet count of $<50 * 109 / \mathrm{L}$ were most at risk (aOR of 2.19 (1.01-4.72)) compared to the reference group with normal platelet counts; the aOR was $1.20(0.77-1.87)$ for the 50-99*109/L platelet count group, and 1.30 (1.09-1.55) for the 100-149*109/L platelet count group. Plateletcrit was associated with SPPH (aOR 1.15 (1.08-1.21) per 0.05\% decrease), and, although rarely present, a PDW [?]23\% $(\mathrm{n}=22)$ also increased the odds of SPPH (aOR 6.13 (2.29-16.4)). Conclusions: Low platelet count, low plateletcrit, and a PDW [?]23\% were associated with the occurrence of SPPH, independent of common PPH risk factors.
\end{abstract}

\section{Hosted file}

Platelets SPPH main article.pdf available at https://authorea.com/users/373723/ articles/491332-platelet-count-and-indices-as-postpartum-haemorrhage-risk-factors-aretrospective-cohort-study

\section{Hosted file}

Table 1. Baseline table.pdf available at https://authorea.com/users/373723/articles/491332platelet-count-and-indices-as-postpartum-haemorrhage-risk-factors-a-retrospectivecohort-study

\section{Hosted file}

Table 2. SPPH odds ratio's.pdf available at https://authorea.com/users/373723/ articles/491332-platelet-count-and-indices-as-postpartum-haemorrhage-risk-factors-aretrospective-cohort-study

\section{Hosted file}

Table 3. SPPH odds ratio's stratified.pdf available at https://authorea.com/users/373723/ articles/491332-platelet-count-and-indices-as-postpartum-haemorrhage-risk-factors-aretrospective-cohort-study 


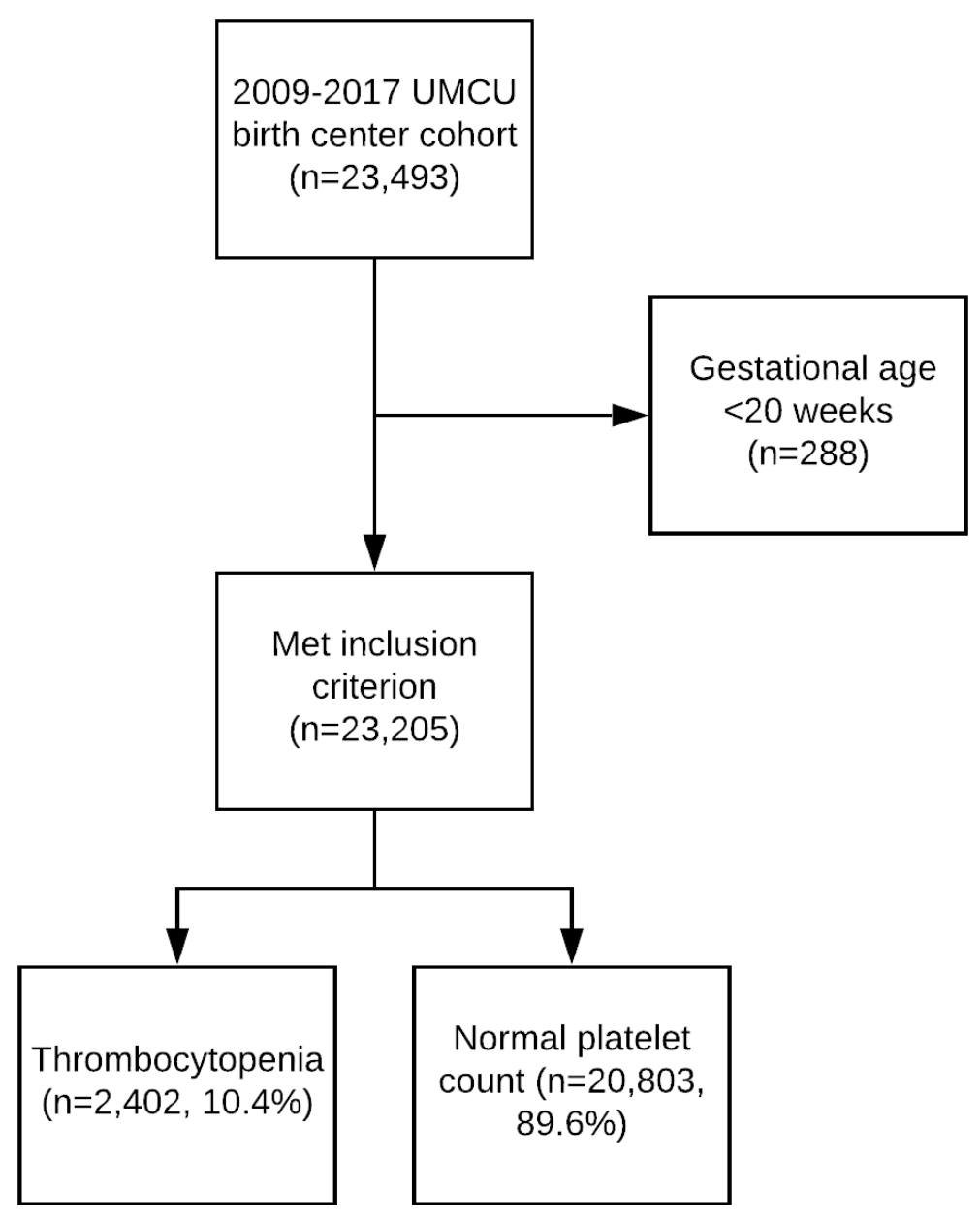



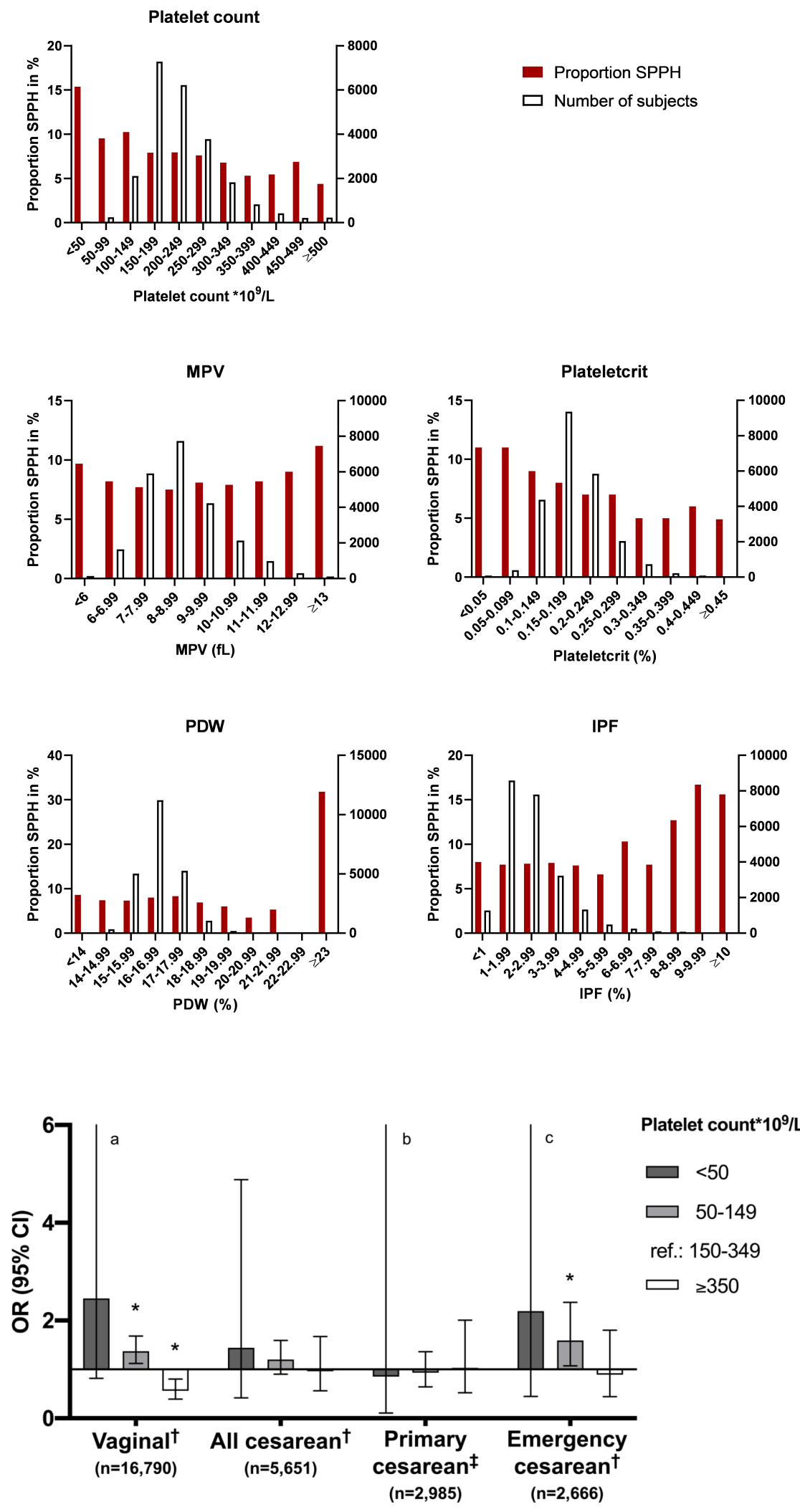